\title{
EL COLEGIO DE NIÑOS DESAMPARADOS DE SANTA ISABEL LA REAL DE MADRID: ORIGEN, CONSTRUCCIÓN Y PRIMERA ORNAMENTACIÓN (1592-1610)
}

\author{
RoBerto MuÑoz Martín ${ }^{1}$ \\ Conservador de Museos Estatales, Madrid
}

\begin{abstract}
Los años que transcurren desde la creación por parte de Felipe II del Colegio de Santa Isabel, hasta la llegada de la comunidad de monjas que lo habitan, es bastante desconocido y confuso. A través de la documentación, en especial de un inventario inédito de 1601, se aporta información relevante acerca del funcionamiento del hospicio y de algunas obras de arte que aún hoy día se guardan en sus muros. Destaca la descripción de la iglesia de la fundación, que se creía nunca existió como tal, y se aportan datos acerca de los bienes muebles que en ella estuvieron.
\end{abstract}

Palabras clave: Santa Isabel; monasterio; colegio; Felipe II; Felipe III; Gaspar de Quiroga y Vela; fundación; pintura.

\section{THE COLLEGE OF ABANDONED CHILDREN OF SANTA ISABEL LA REAL DE MADRID: ORIGIN, CONSTRUCTION AND FIRST ORNAMENTATION (1592-1610)}

The years that pass from the creation by Felipe II of the Colegio de Santa Isabel, until the arrival of the community of nuns that inhabit it, is quite unknown and confusing. Through the documentation, especially an unpublished inventory of 1601, relevant information is provided about the operation of the hospice and some works of art that are still kept on its walls today. The description of the church of the foundation stands out, which was believed to have never existed as such, and data are provided about the movable assets that were there.

Key words: Santa Isabel; monastery; school; Felipe II; Felipe III; Gaspar de Quiroga y Vela; foundation; painting.

Cómo citar este artículo / Citation: Muñoz Martín, Roberto (2021) "El colegio de niños desamparados de Santa Isabel la Real de Madrid: origen, construcción y primera ornamentación (1592-1610)”. En: Archivo Español de Arte, vol. 94, núm. 373, Madrid, pp 1-14. https://doi.org/10.3989/aearte.2021.01

Hablar de la historia del convento de Santa Isabel la Real de Madrid es hacerlo de una institución señera, que ha soportado, con mayor o menor fortuna, los avatares del tiempo durante más de 400 años, pero cuya primera etapa está aún por estudiarse. Lo que hoy día es un convento y un colegio en uno de los centros neurálgicos y culturales de la ciudad, fue en sus inicios una villa de recreo alejada del núcleo administrativo de la Corte, que pasó a recogimiento de niños y niñas pobres, por orden del rey Felipe II (1527-1598) y, posteriormente, a los ya citados centros religioso y docente.

Los orígenes de esta institución se remontan a la compra de unos terrenos en el año 1573. Esta adquisición fue realizada por Antonio Pérez (1540-1611), secretario del rey Felipe II al convento

\footnotetext{
${ }^{1}$ Roberto.Munoz.Martin4@gmail.com / ORCID iD: https://orcid.org/0000-0003-4684-0809
} 
de la Concepción Francisca de Madrid, por la poca utilidad de estos a la orden religiosa ${ }^{2}$. Diez días después de su compra, se pidió licencia para edificar esta superficie. Al no haber ningún edificio colindante, se permitía la libre disposición del espacio para la creación de una villa de recreo y unas huertas o jardines a su alrededor ${ }^{3}$.

Esta posesión fue denominada vulgarmente como "La Casilla" y no despertó un especial interés en el Madrid de la época. No conocemos el nombre de su arquitecto ni tampoco su año preciso de construcción, aunque es obvio que debió de finalizarse antes de 1578, momento en que Antonio Pérez comenzó a tener problemas con la justicia, que culminarán con su exilio del país ${ }^{4}$. Los relatos contemporáneos conservados detallan una finca con grandes espacios, acogedores y lujosos:

Era amplia, cuadrada, con cuatro torreones en los extremos y grandes ventanas abiertas en dos hileras simétricas. La entrada se hacía a través de un enorme patio empedrado, con poyos de mampostería, dos aljibes de piedra berroqueña y multitud de argollas de hierro que adornaban cabezas de fieras para atar las caballerizas ${ }^{5}$.

Esta disposición, conocida por descripciones, algunas cercanas a la sorna por su comparación con templos árabes, no aporta noticias del edificio ni de su contenido ${ }^{6}$. Son otros documentos los que ofrecen estos datos, como los inventarios del proceso judicial e incautación de propiedades del secretario a favor de la Corona ${ }^{7}$. Estos escritos dan a conocer las diferentes estancias que componían "La Casilla" y la calidad y variedad de los objetos que la decoraban. En ellos se describe una colección de hasta 130 pinturas, esculturas, muebles, tapices o cristales venecianos. De todos los registros, llama la atención la escasa presencia de pintura de temática religiosa, expuesta más por su calidad artística o material que por su función piadosa, así como la ausencia de cualquier estancia, capilla u oratorio, dedicado a la oración y al recogimiento religioso ${ }^{8}$.

Según avanzaba el proceso judicial de Antonio Pérez, este edificio, junto con otros, intentó ser vendido por el secretario. En un documento remitido a Felipe II en $1578^{9}$, se refleja tal venta, aunque no hubo constancia material hasta el 28 de agosto de 1581. Es en este momento cuando aparece un tal Baltasar Cataño, ofreciendo una gran suma de dinero por la compra de todas las propiedades de Pérez ${ }^{10}$. Sin embargo, el contrato de adquisición no obtuvo la aprobación del rey y el secretario real traspasó esta venta a la princesa de Éboli el 8 de marzo de $1582^{11}$. Aunque estos movimientos fueron rápidos, en 1590 fue dictada sentencia contra Antonio Pérez e incautados todos sus bienes a favor de Felipe II, entre ellos "La Casilla""

A pesar de la complejidad que entrañaba dar uso a un edificio tan grande y algo lejos del Alcázar madrileño, el monarca tuvo claro, desde un primer momento, la intención de establecer en este lugar algún tipo de obra piadosa o de beneficencia al servicio del pueblo. Por ello, dos años

\footnotetext{
${ }^{2}$ Escritura de venta de una tierra en Madrid a favor de Antonio Pérez otorgada por el monasterio y convento de la Concepción Francisca, 17 de julio de 1573, Archivo Histórico Nacional (en adelante AHN), Consejos, 50232, Exp. 8. Publicado en González Palencia, 1918: 365.

${ }^{3}$ Escritura otorgada por Pedro Álvarez, teniente de guarda de la villa de Madrid, por la que se concede licencia a Hernando de Escobar para labrar una tierra en la parroquia de San Sebastián y edificar en ella una casa, 27 de junio de 1573, AHN, Consejos, 50232, Exp. 9. Publicado en González Palencia, 1918: 366.

${ }^{4}$ Marañón y Posadillo, 1948: 32.

${ }^{5}$ Ezquerra del Bayo, 1926: 117.

${ }^{6}$ Zapata, 1859: 246.

7 Delaforce, 1982: 742-752.

8 Delaforce, 1982: 751.

9 González Palencia, 1918: 353.

${ }^{10}$ Escritura de concierto y venta por la que Antonio Pérez se compromete a comprar la villa de Pareja (Cuenca) y Baltasar Cataño las tierras, las casas y los lienzos que aquel tiene en Madrid, 28 de agosto de 1581, AHN, Consejos, 50232, Exp. 3. Publicado en González Palencia, 1918: 368.

${ }^{11}$ Venta de unas casas, tierras y lienzos que Baltasar Cataño habia comprado a Antonio Pérez en favor de Ana de Mendoza y de la Cerda, princesa de Éboli, y de su hijo Diego de Silva y de Mendoza, duque de Francavilla, 17 de diciembre de 1581, AHN, Consejos, 50232, Exp. 4. Publicado en González Palencia, 1918: 354.

${ }^{12}$ Ungerer, 1974-75: 70.
} 
después de la incautación de la finca, funda un recogimiento y colegio para niñas y niños huérfanos y desatendidos, que recibirá el nombre de Santa Isabel, en honor de Santa Isabel de Hungría y de su hija Isabel Clara Eugenia ${ }^{13}$. El lugar debió de acondicionarse durante un tiempo, pues el 6 de agosto de 1595 se inauguró la obra "comenzándola con piedras vivas y muertas", lo que señala que se estableció el colegio sobre edificios ya existentes junto a otros de nueva planta. La primera misa se ofició el 18 de diciembre de ese mismo año ${ }^{14}$.

Según las crónicas y documentos testimoniales de la época, el recogimiento se mantenía con las rentas del rey y aquellas legadas por el Cardenal Arzobispo de Toledo, don Gaspar de Quiroga y Vela (1512-1595), debido al especial afecto que sentía por esta y otras obras piadosas de su villa natal (Madrigal de las Altas Torres), de Salamanca, Madrid y Toledo. La renta asignada por el purpurado ascendió a los seis mil ducados y aunque se dice que se entregó a su muerte, acaecida en 1594, no fue realmente aplicada hasta 1595 , por problemas y gestiones con sus herederos ${ }^{15}$.

Estos colegiales recibían una educación bajo la dirección de seglares y una manutención adecuada $^{16}$. Además, en la planta baja de un edificio cercano se encontraba un taller de tapicería propiedad del salmantino Pedro Gutiérrez, en el que colaboraban niños del recogimiento. Este dato es curioso, porque muestra cómo la fundación regia actuaba no solo como hogar para huérfanos y desatendidos, sino también como lugar de enseñanza de un oficio para subsistir en el futuro ${ }^{17}$.

Parece que este primer taller, costeado por el monarca en 1598, tuvo bastante éxito y trabajó de forma ininterrumpida, pues llegó a emplear hasta 50 aprendices del colegio y potenció la introducción de empleos similares, como un obrador de pasamanería entre 1604 y $1609^{18}$. En 1602 murió su dueño y el negocio pasó por varios propietarios, el último, Antonio Cerón de Barrientos, quien trabajó allí hasta 1610, momento en que por orden de Felipe III (1578-1621), llegaron unas monjas, agustinas recoletas, para fundar un patronato regio, y se tuvieron que desmontar los telares, a excepción de uno para servicio del rey ${ }^{19}$.

A partir de entonces, la historia del edificio y de su institución sufrieron intensas modificaciones, tanto físicas como normativas. Las religiosas prescindieron de los varones del recogimiento y asumieron el gobierno del colegio hasta el año 1649, momento en que Felipe IV (1605-1665) las liberó de esta carga, y se diferenció, por una parte, el Colegio de Santa Isabel y por otra el convento de agustinas recoletas del mismo nombre ${ }^{20}$.

Como sucedió con "La Casilla", esos escasos años que transcurrieron entre la creación del recogimiento por parte de Felipe II y la llegada de las religiosas por orden de Felipe III y su esposa Margarita de Austria-Estiria (1584-1611), no cuentan con mucha documentación que indique qué ocurrió con la antigua villa de recreo, ni cómo fue reaprovechado este edificio para satisfacer unos fines totalmente diferentes.

Por ello, resulta particularmente interesante una colección de 62 cuadernillos, escritos en 1909 por Francisco Pérez Sierra y conservados en el Archivo General de Palacio de Madrid, en los que se cuenta la historia del real patronato de Santa Isabel desde sus inicios, y en los que se transcriben algunos documentos que posteriormente se perdieron ${ }^{21}$. Este manuscrito inédito, adquirido en la II República, es de los pocos testimonios que quedan de parte del archivo del convento ya que este lugar, junto con el resto de dependencias conventuales, fueron destruidos en marzo de $1936^{22}$.

13 Sáenz Ruíz-Olalde, 1990: 64.

14 Sáenz Ruíz-Olalde, 1990: 64-65.

15 Marañón y Posadillo, 1948: 50.

${ }^{16}$ Libro del dinero que entra y sale del recogimiento de Santa Isabel, Archivo General de Palacio, Madrid (AGP), Fundaciones, Colegio, caja 12. Publicado en Cruz Yábar, 1996: 27.

${ }_{17}$ Cruz Yábar, 1996: 29.

${ }^{18}$ Cruz Yábar, 1996: 36.

19 Cruz Yábar, 1996: 30.

${ }^{20}$ Sánchez Hernández, 1990: 36.

${ }^{21}$ Historia del real Patronato de Santa Isabel, 1909, Archivo General de Palacio (AGP), Santa Isabel, Caja 301, Legajo 9/1, Apéndice II.

22 Robles Muñoz, 2018: 238. 
En uno de estos pliegos se encuentra transcrito el primer inventario del colegio de Santa Isabel, ya que "no ha hallado inventario jurídico [anterior] de los bienes y alhajas que hay para el servicio

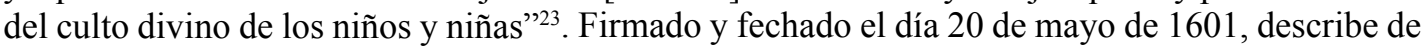
forma minuciosa todo lo que había en aquellas dependencias.

El inventario está dividido por estancias. Comienza con la iglesia y continúa enumerando otras salas como contaduría, sala en la que se detiene de un modo especial para mencionar todos los libros que existen, escuela, refectorio, sastrería, zapatería, guardarropa, dormitorio y enfermería, despensa, cocina, jardines y huertas, pajar y, finalmente, desvanes. Tras esta enumeración de estancias del colegio hace una descripción somera de la casa del portero y, algo más extensa, del cuarto de las mujeres (profesoras seglares), dividiendo el conglomerado en altar, dormitorios, enfermería, refectorio, despensa y cocina. Finaliza dicho registro con un apartado que trata sobre las campanas que están por todo el edificio ${ }^{24}$.

Al ser la iglesia el primer espacio inventariado, es factible que fuera considerado el más relevante del conjunto, pero también por la premura de su inauguración hay que considerarlo algo temporal, aspecto bastante común en edificios reaprovechados. Por tanto, es probable que el templo se construyese a partir de la reordenación de algún salón o galería, porque la antigua villa de recreo no contaba con ninguna estancia dedicada al culto ${ }^{25}$. Teniendo en cuenta las posibilidades del edificio, se trataría de una habitación no muy grande, posiblemente rectangular, de techos bajos y escasa decoración, a la que se sumaría otra sala más pequeña, denominada en la documentación "Capilla de la Anunciación".

No poseemos ninguna representación gráfica que pueda corroborar esta teoría, pero sí contamos con algunas planimetrías casi contemporáneas que sugieren que "La Casilla" no cambió mucho su estructura durante esa época. Estos planos son el denominado Plano de Witt ${ }^{26}$ [fig. 1], realizado entre los años 1622 y 1635 y el más conocido Plano Texeira, de hacia $1656^{27}$ [fig. 2]. Aunque ambos son posteriores, es bastante seguro que las dos planimetrías fueron realizadas antes de la llegada de las monjas al colegio. Por tanto, en sendos documentos se pueden establecer una serie de características comunes que nos ayuden a ver el edificio en su estado original ${ }^{28}$.

Los dos mapas muestran un espacio similar, compuesto por galerías, patios, jardines y huertas, donde el elemento más original son dos grandes torres que asoman a la calle, y que aparecían en las descripciones de "La Casilla". Entre ambas estructuras hay una galería que se sitúa de forma perpendicular. Es muy posible que ese lugar fuera el más adecuado para situar la primitiva iglesia del colegio y donde, posteriormente se edificarán los templos, tanto el de Fray Alberto de la Madre de Dios como el construido después por Juan Gómez de Mora, proyecto que se mantiene en la actualidad ${ }^{29}$.

Según el inventario, el ornamento y enseres del templo eran limitados, centrados en aspectos esenciales de la liturgia diaria. Además, el documento divide la totalidad de objetos en dos lotes, según su procedencia. El primero hace referencia al legado testamentario del Cardenal Arzobispo don Gaspar de Quiroga y Vela y el segundo, a la dote proveniente de la Casa Real.

Con respecto al primer lote hay varios detalles a tener en cuenta, como la continua referencia a que todo el legado del prelado era viejo o estaba usado, caso de los ornamentos textiles litúrgicos,

\footnotetext{
${ }^{23}$ Historia del real Patronato de Santa Isabel, 1909, Archivo General de Palacio (AGP), Santa Isabel, Caja 301, Legajo 9/1, Apéndice II, p. 2.

${ }^{24}$ Historia del real Patronato de Santa Isabel, 1909, Archivo General de Palacio (AGP), Santa Isabel, Caja 301, Legajo 9/1, Apéndice II, pp. 2-30.

${ }^{25}$ Delaforce, 1982: 742.

26 “Madrid. Planos de población. (1622)". En: <https://www.ign.es/web/catalogo-cartoteca/resources/html/001484. html> [30-04-2020].

27 "Topographia de la Villa de Madrid descrita por Pedro Texeira. Año 1656". En: <https://www.ign.es/web/catalogo-cartoteca/resources/html/001602.html> [25-04-2020].

${ }_{28}$ Molina Campuzano, 1960: 253.

29 Tovar Martín, 1975: 322.
} 
Fig. 1. Frederik de Wit Excudit. La Villa de Madrid Corte de los Reyes Católicos de Espanna (detalle. Colegio Santa Isabel). Instituto Geográfico Nacional. Cartoteca. 32-A-1.

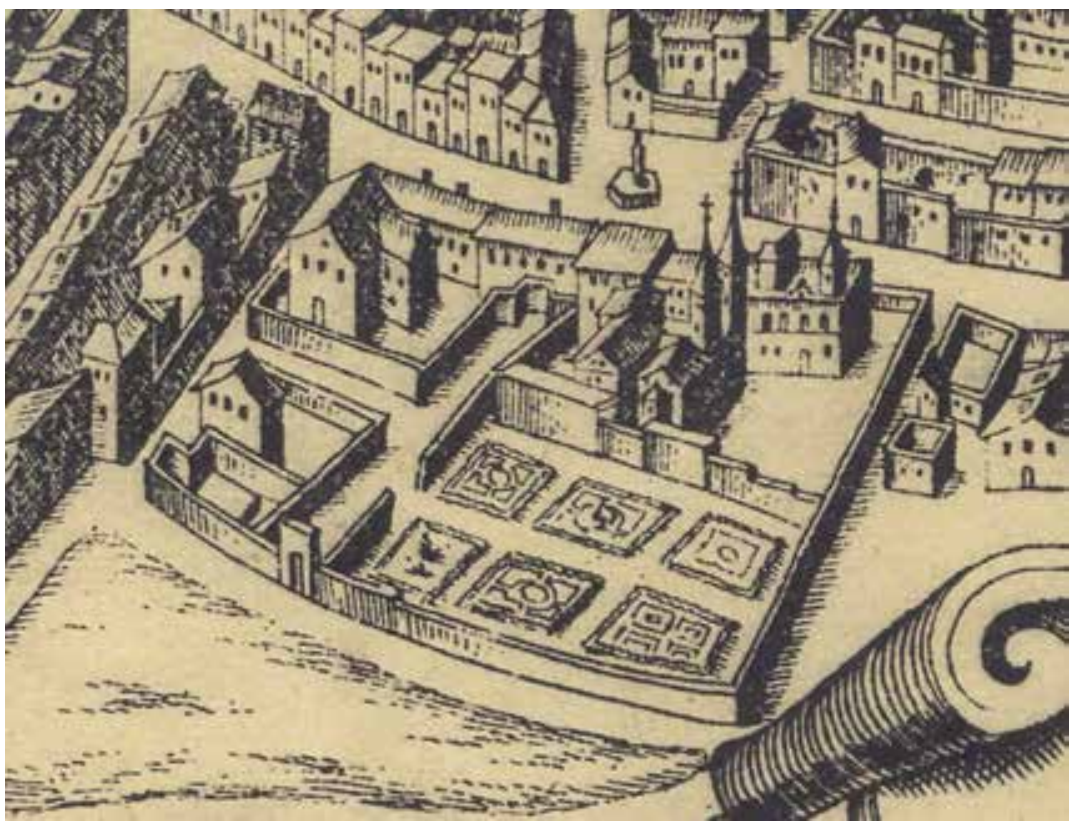

Fig. 2. Pedro Texeira. Topografia de La Villa de Madrid: Mantua Carpetanorum sive Matritum Ubs Regia (detalle. Colegio Santa Isabel). Instituto Geográfico Nacional. Cartoteca. 10-A-2.

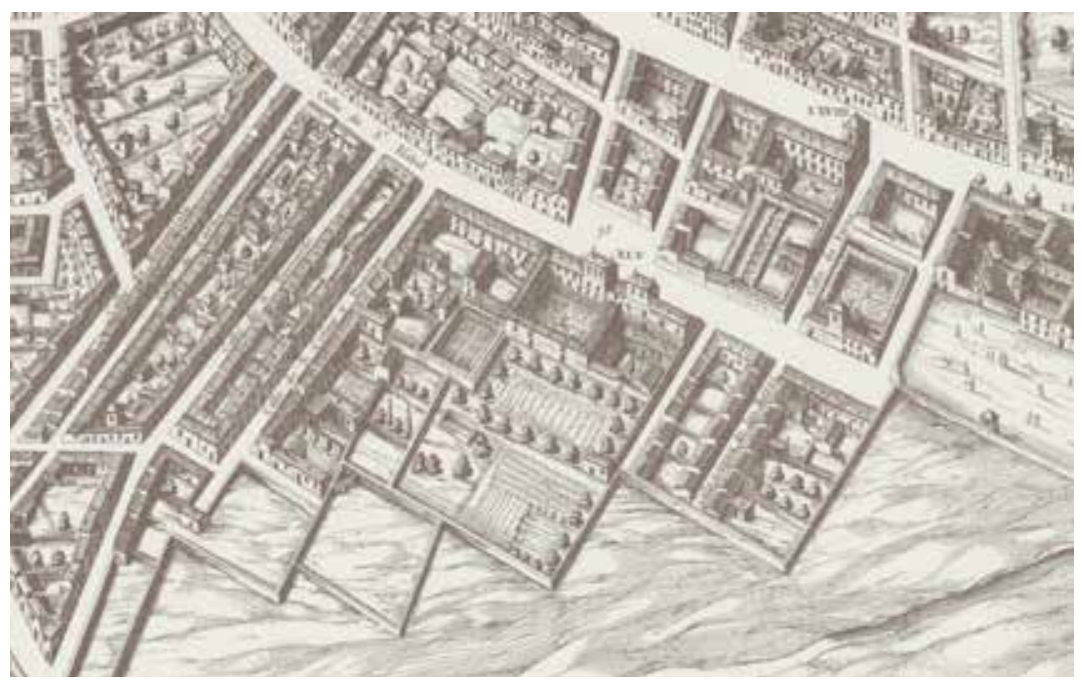

tanto para el oficiante como para asistentes ${ }^{30}$. Junto a estos objetos, había otros elementos auxiliares, como una alfombra o una cortina, esta última utilizada en la reja de la mencionada capilla de la Anunciación ${ }^{31}$.

Aparte de estos objetos, el listado se completa con piezas de otros materiales, como metal o madera, una colección de libros de liturgia y estampas, destacando un misal veneciano de 1582 y una serie de lienzos con figuras de orantes, a los que habría que sumar la renta ya comentada que no está descrita en este documento ${ }^{32}$.

${ }^{30}$ Historia del real Patronato de Santa Isabel, 1909, Archivo General de Palacio (AGP), Santa Isabel, Caja 301, Legajo 9/1, Apéndice II, p. 12.

31 Historia del real Patronato de Santa Isabel, 1909, Archivo General de Palacio (AGP), Santa Isabel, Caja 301, Legajo 9/1, Anexo 1, p. 12.

${ }^{32}$ Álvarez y Baena, 1786: 186. 
En cuanto a la segunda división, relativa a lo que el rey dio al colegio, se debe considerar que dichos bienes fueron entregados por Felipe III y no por su padre, ya que el inventario no menciona en ningún momento a dicha figura como su legatario. Refuerza esta teoría el registro de un cáliz limosnero ${ }^{33}$, con cubrecopa, patena y estuche para proteger el conjunto, con la inscripción: "Philippus tercius Hispaniarum Rex" ${ }^{\prime 4}$. Además, se indica que fue entregado en 1599, un año después de la muerte de Felipe II.

Este cáliz limosnero se completaba con otro vaso blanco con su patena dorada, una serie de lámparas y candelabros, acetre, campanilla, oliera con plumilla y tapador, así como otras piezas con menor interés como una tarima, unos taburetes u otro atril que se unió a los ya legados por el purpurado. También se repiten una serie de ornamentos textiles de sarga para diversas celebraciones: blanco, rojo, verde, morado y negro.

Aparte de lo ya comentado, en el listado se hallan una serie de piezas de posible relevancia artística, como un altar portátil, un relicario con custodia y cruz pequeña y hasta tres retablos en diversos lugares de la iglesia. El mayor estaba situado en la capilla de la Anunciación y era "grande hasta cuatro varas de ancho y tres de alto, y con su marco por detrás, sin polsera ni guarnición" 35 . La conversión de las varas castellanas en metros daría como resultado un retablo de, aproximadamente, 3,30 metros de ancho por 2,50 metros de alto. Este dato muestra que era grande en comparación con los demás, pero que se adecuaba a las medidas de un salón preexistente, más pequeño de lo que se podría esperar en una iglesia de nueva construcción.

Los otros dos se disponían en la nave del templo y en el presbiterio, compartiendo lugar con una pintura de la Magdalena. El de la nave era "mediano, con unas puertas y marco dorado, de pintura flamenca" 36 . Lo escueto de la cita nos impide conocer de forma precisa de qué obra se trataba, al no existir actualmente ninguna con esas características en el inventario de bienes vigente del convento. Sin embargo, sí que se conservan dos tablas del siglo XVI, las más antiguas de pintura de la institución, y de aparente ejecución flamenca. Una de ellas representa a José de Arimatea reclamando el cuerpo de Cristo $(103 \times 42 \mathrm{~cm})$ [fig. 3] mientras que la otra es un busto de Jesús, que recibe el nombre de Ecce Homo $(41 \times 32,5 \mathrm{~cm})^{37}$ [fig. 4]. Ambas pinturas son óleos sobre tabla, y poseen una factura similar entre ellos, tanto en aspectos compositivos como formales.

Estas dos obras, que ahora están separadas, debieron formar conjunto y reinterpretar, con alguna variante, un tríptico titulado Ecce Homo $(109 \times 167 \mathrm{~cm})$, del denominado Maestro de la Santa Sangre, de hacia 1520-1525, conservado en el Museo Nacional del Prado [fig. 5] ${ }^{38}$. Los fragmentos de Patrimonio Nacional copian, de manera más tosca y con menor detalle, tanto las figuras de los

33 Historia del real Patronato de Santa Isabel, 1909, Archivo General de Palacio (AGP), Santa Isabel, Caja 301, Legajo 9/1, Anexo 1, p. 5.

${ }^{34}$ Panizo Delgado, 2012: 241. Martín, 1979: 15. Este tipo de pieza litúrgica se denominaba "limosnero regio", por ser entregado por los reyes en la Misa Mayor del día de la Epifanía. La ofrenda consistía en tres cálices con los que se quería recordar el oro, el incienso y la mirra que los Reyes Magos ofrecieron al niño Jesús. Solían estar grabados con el nombre del rey, el escudo de la monarquía, el nombre del limosnero mayor de su majestad y la fecha correspondiente. Después los cálices se regalaban por iniciativa real a iglesias, conventos o dignatarios eclesiásticos. En el inventario de la iglesia solo se mencionan dos cálices, ofrecidos en 1599, uno ya descrito y el otro liso, blanco y con el escudo real grabado. La obra fue entregada el día de Reyes, siendo Limosnero Mayor el señor don Álvaro de Carvajal, que sucedió en este oficio y en la protección de esta obra y casa al ilustrísimo señor don García de Loaysa y Girón, antiguo arzobispo de Toledo, muerto el año anterior. La pista de este cáliz se pierde a partir de esta mención, y ya no aparece descrito con posterioridad en la escasa documentación que se conserva en el convento.

${ }_{35}$ Historia del real Patronato de Santa Isabel, 1909, Archivo General de Palacio (AGP), Santa Isabel, Caja 301, Legajo 9/1, Anexo 1, p. 3.

${ }^{36}$ Historia del real Patronato de Santa Isabel, 1909, Archivo General de Palacio (AGP), Santa Isabel, Caja 301, Legajo 9/1, Anexo 1, p. 4.

${ }^{37}$ La tabla del Ecce Homo, con número de clasificación PI-630737, se conserva en el Zaguán de la planta primera y el José de Arimatea, con identificación PI-630804, en el Refectorio de la planta segunda.

38 "Maestro de la Santa Sangre. Ecce Homo". En: https://www.museodelprado.es/coleccion/obra-de-arte/eccehomo/868fdb47-e6df-4dff-b1 f0-912944b14aaf?searchid=050a8fdd-1e4f-4f69-df3e-44da841ac3e5 [11-10-2020]. El tríptico del Museo del Prado, con una cronología de hacia 1520-1525, tiene el número de catálogo P001559 y se adquirió en el siglo XIX en Valencia para Fernando VII. 


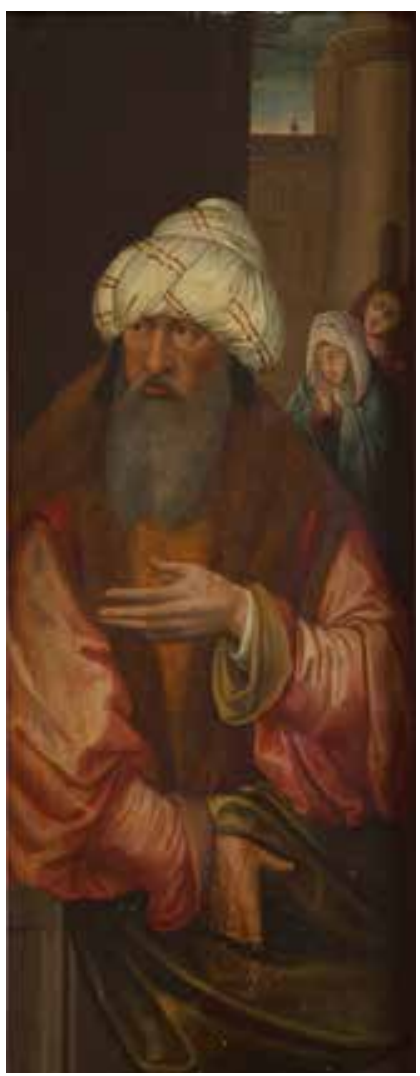

Fig. 3. Anónimo seguidor del Maestro de la Santa Sangre. José de Arimatea reclamando el cuerpo de Cristo (aquí Poncio Pilatos), h. 1525.

Madrid, Convento de

Santa Isabel (PI-

630804). (Patrimonio

Nacional.

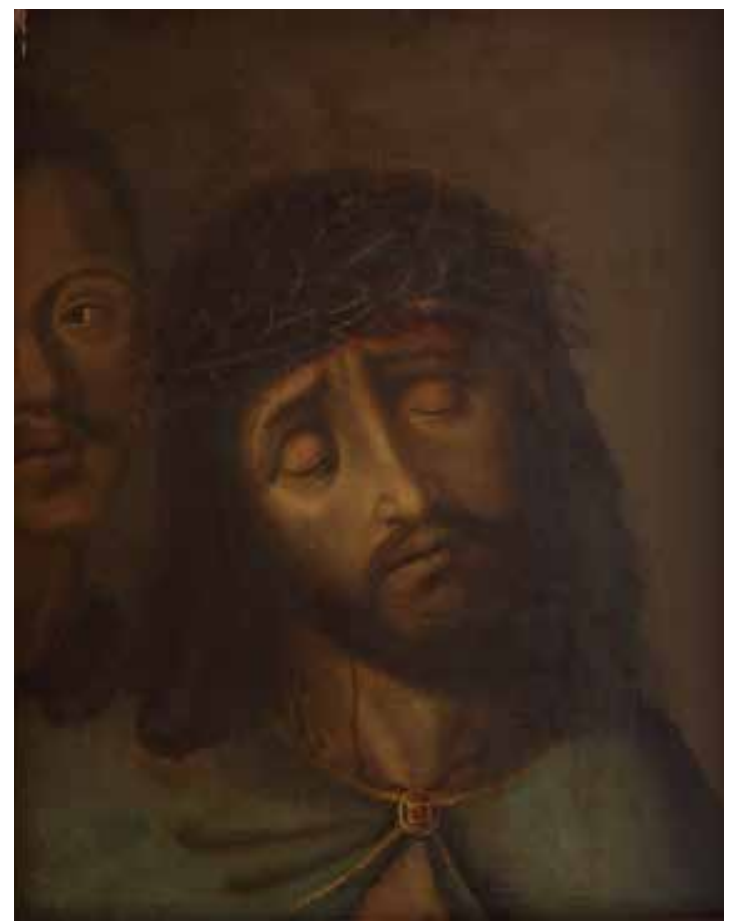

Fig. 4. Anónimo seguidor del Maestro de la Santa Sangre. Ecce Homo, h. 1525. Madrid, Convento de Santa Isabel (PI-630737). (P) Patrimonio Nacional.

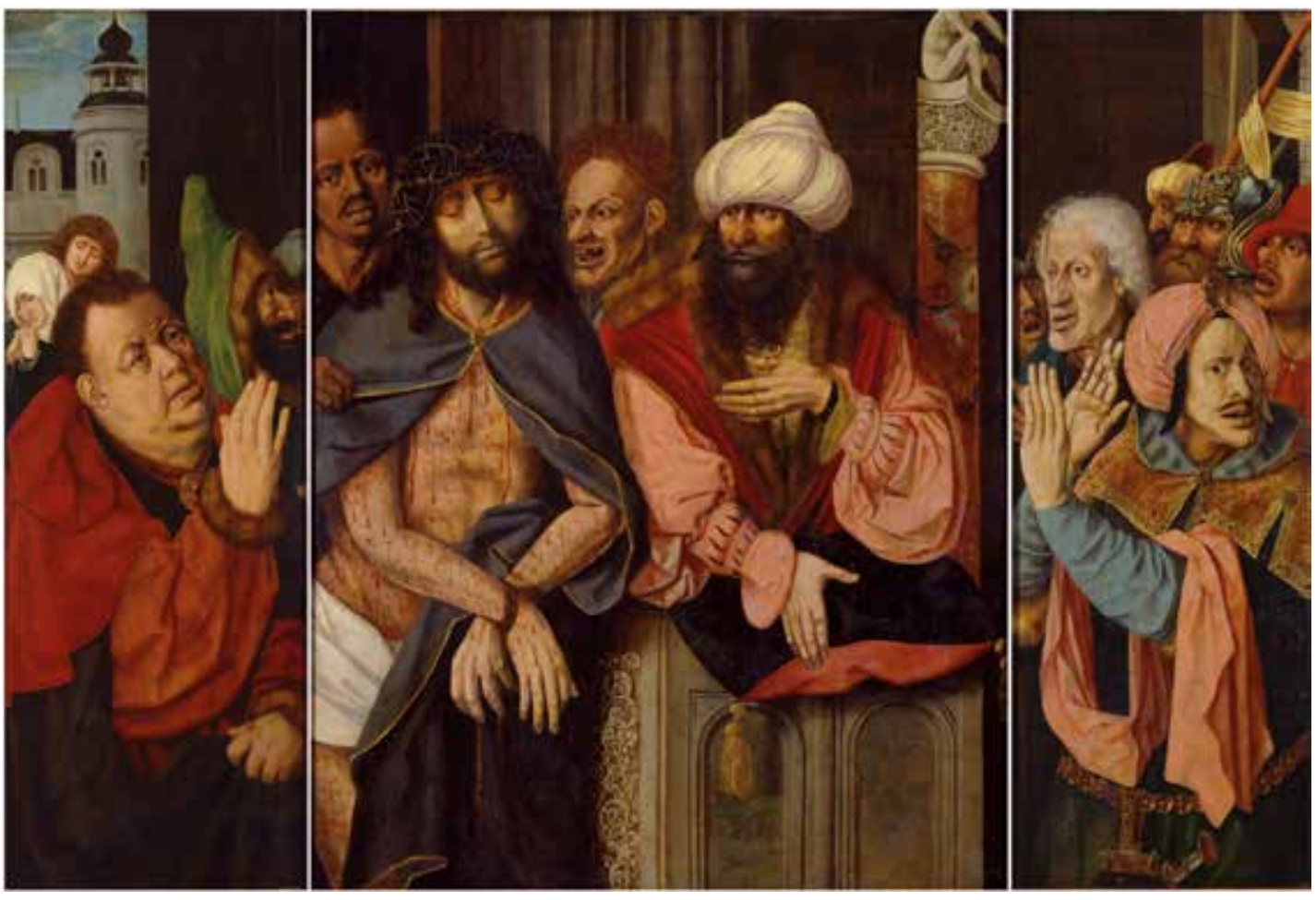

Fig. 5. Maestro de la Santa Sangre. Ecce Homo, 1520-1525. Madrid, Museo Nacional del Prado (P001559).

Archivo Español de Arte, vol. XCIV, n. ${ }^{\circ} 373$, pp. 1-14, enero-marzo 2021 ISSN: 0004-0428, eISSN: 1988-8511, https://doi.org/10.3989/aearte.2021.01 
personajes principales, como aquellos más anecdóticos situados en segundo plano, como la Dolorosa, San Juan Evangelista o las arquitecturas, presentes al fondo de la composición, en la tabla izquierda del Museo del Prado o el personaje situado tras Jesús de ambas composiciones.

No obstante, es más probable que la pintura considerada como José de Arimatea sea en realidad Poncio Pilatos como en el tríptico del Museo del Prado. Las ropas orientales del personaje, así como el gesto de señalar la figura de Cristo, aludirían al acto del prefecto romano recogido en la Biblia. Además, José de Arimatea no estaría aún presente reclamando el cuerpo de Jesús ya que este no estaba muerto todavía.

Esta semejanza también se advierte en las medidas de las dos obras. Mientras que la tabla del supuesto José de Arimatea tiene, como se ha comentado, $103 \times 42 \mathrm{~cm}$, el tríptico del Maestro de la Santa Sangre coincide prácticamente en altura y el ancho del cuerpo central tendría una medida de unos $83 \mathrm{~cm}$ de ancho, espacio que sería perfectamente ocupado por ambas piezas de Santa Isabel, sobrando apenas unos centímetros que completarían las figuras cortadas ${ }^{39}$. Además, aunque no se conocen las medidas del tríptico original del convento madrileño, la estrecha relación de las tablas con la obra del Museo del Prado acercan esta al concepto "mediano" que se menciona en el inventario de $1601^{40}$.

Una vez identificadas estas posibles piezas como parte del tríptico citado, quedaría estudiar aspectos técnicos y formales de ambas obras, tales como el estudio de la madera con que está realizado el soporte o de los pigmentos, a fin de conocer si se trata de una pintura flamenca adscrita al importante obrador que este pintor anónimo flamenco tenía en Brujas o, por el contrario, alguna copia española realizada en el siglo XVI, bien utilizando de modelo el original, bien alguna estampa.

El último retablo, situado en el altar mayor, llama la atención por ser la única obra que representa la advocación del hospicio y colegio madrileño, La Visitación de la Virgen María a santa Isabel estando ambas encinta. Se describe como:

Un retablo en el altar, que es en lienzo de pincel, que es la Visitación de Santa Isabel, con sus dos puertas, en las cuales esta pintado, de pincel, en la una San Eugenio y en la otra San Ildefonso, por la parte de adentro, y cerrados las dichas puertas están pintados, por la parte de afuera, la historia de la Visitación, de pintura blanca, y dorados la moldura y escultura del dicho retablo ${ }^{41}$.

Menor en tamaño que el de la capilla de la Anunciación, es curiosa su estructura de tríptico, algo tardía para la moda del momento, de grandes composiciones que ocupaban la totalidad de sus muros y múltiples representaciones situadas en varios cuerpos. Aquí, sin embargo, hay una imagen principal con dos puertas. Abierto se observaba la advocación del recogimiento, encuadrada por dos santos y, al cerrarse, la escena de la Visitación, esta vez en grisalla.

Técnicamente, se deja claro que tanto la parte central como las dos puertas estaban realizadas en pintura sobre lienzo ensambladas sobre una estructura de madera y no en tabla como se acostumbraba en este tipo de piezas, tanto por moda venida de Italia como para abaratar costes. Aunque se piense que era un modelo inusual, en realidad fue más frecuente de lo que conservamos hoy día. Antecedentes importantes serían las grandes puertas de pintura bifaz de algunos retablos aragoneses del siglo XVI o las de los altares estacionales del claustro y los armarios relicarios de San Lorenzo de El Escorial, pintadas sobre madera en ambos casos.

Como se ha visto con las pinturas flamencas del Ecce Homo, en el inventario actual del patronato real, no figuran demasiadas obras del siglo XVI o primeros años del XVII. Diferentes conflictos, como la Guerra de la Independencia o la Guerra Civil, tuvieron una gran incidencia en

\footnotetext{
${ }_{39}$ Medida tomada del total aportado por la web del museo $(109 \mathrm{~cm}$ de alto por $167 \mathrm{~cm}$ de ancho) y dividido dicho ancho en cuatro partes, correspondiendo dos partes a cada una de las puertas y dos a la tabla central.

${ }^{40}$ Este aspecto se acentúa al relacionar las medidas de un retablo "grande", que sí son aportadas en el inventario y que apenas sobrepasan los tres metros de ancho y los dos y medio de alto, como se mencionan en la nota 34.

${ }^{41}$ Historia del real Patronato de Santa Isabel, 1909, Archivo General de Palacio (AGP), Santa Isabel, Caja 301, Legajo 9/1, Anexo 1, p. 3.
} 


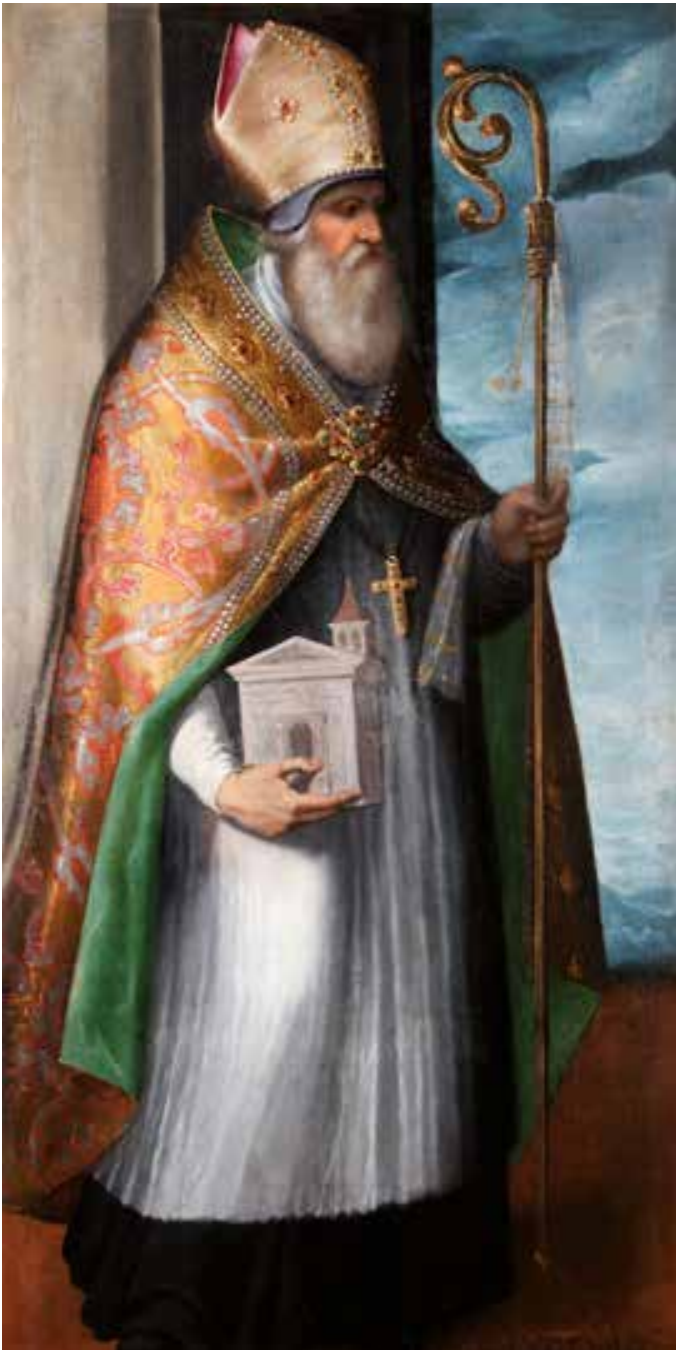

Fig. 6. Eugenio Cajés. San Eugenio, h. 1599-1601. Madrid, Convento de Santa Isabel (PI-630840). (C) Patrimonio Nacional.

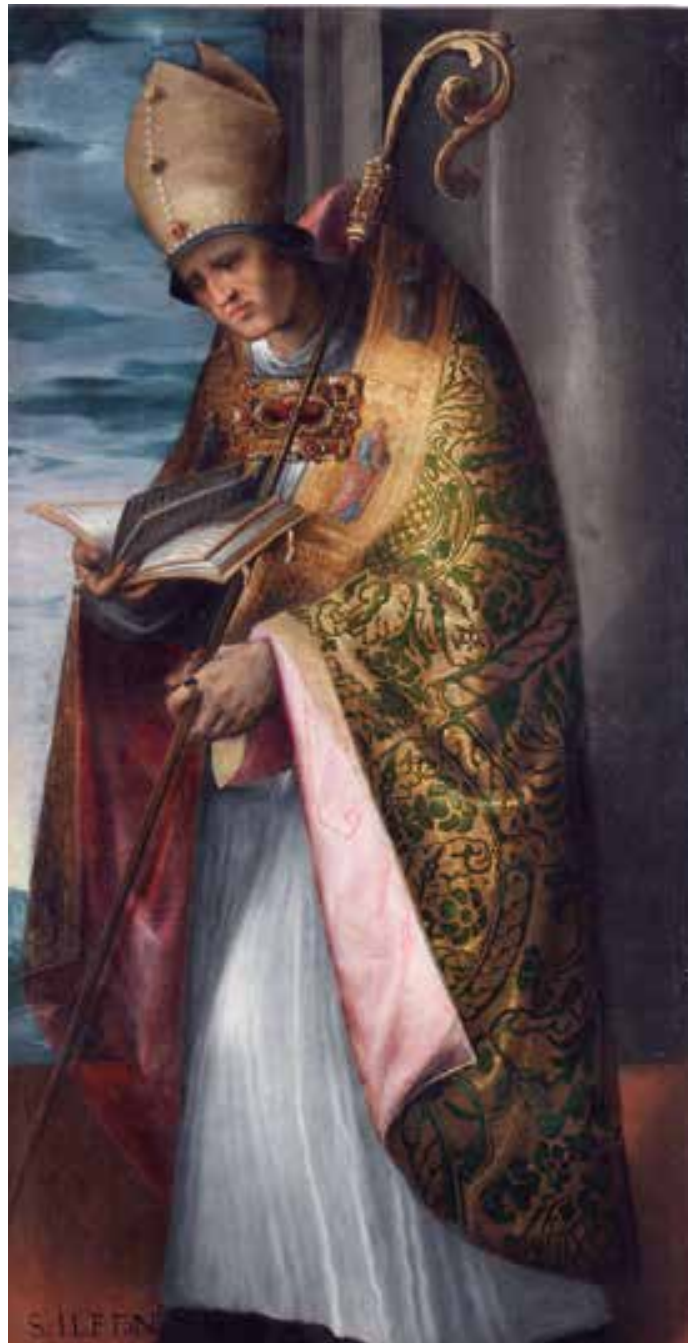

Fig. 7. Eugenio Cajés. San Ildefonso, h. 1599-1601. Madrid, Convento de Santa Isabel (PI-630839). (C) Patrimonio Nacional.

esta comunidad de religiosas y dispersaron, cuando no destruyeron, gran cantidad de obras que guardaban. Las escasas que se conservan son fragmentarias y están muy descontextualizadas.

Sin embargo, entre estos bienes se encuentran dos pinturas que llaman la atención por su calidad y porque podrían asimilarse al tríptico citado. Se trata de dos óleos sobre lienzo, formando pareja, de medidas idénticas $(141 \times 68 \mathrm{~cm})$, que representan a sendos padres de la iglesia hispanovisigoda afrontados entre sí. A sus pies están sus nombres inscritos en letra capital: "S. EVGENIO" y "S. ILEFoNSo" ${ }^{2}$. Las pinturas, que parecen estar recortadas, a tenor del poco espacio disponible alrededor de ellas, no solo encajarían con la descripción de las figuras que se encontraban en las alas del retablo, sino también con el estilo de inicios del reinado de Felipe III [figs. 6 y 7].

${ }^{42}$ Las dos pinturas pertenecen a Patrimonio Nacional y están situadas en la iglesia del Convento de Santa Isabel de Madrid. Como curiosidad, mientras el nombre de san Ildefonso estaba visible, el de san Eugenio estaba parcialmente borrado y oculto bajo repintes que la restauración del año 2002 sacó a la luz y rehízo. Son dos óleos sobre lienzo con números de inventario PI-00630839 para la pintura de San Ildefonso y PI-00630840 para San Eugenio. 
Los dos santos están cubiertos con ricas capas pluviales con decoración vegetal, mitras enjoyadas y portan, cada uno en su mano izquierda, báculos muy similares, con sendas macollas con arquitecturas en su parte superior y rematados con una cabeza con decoración vegetal cada uno. En el caso de San Eugenio, lleva un modelo de iglesia en su mano derecha y una cruz pectoral asomando bajo la capa, cuyos extremos une en el pecho con un formal de líneas florales.

San Ildefonso lleva un libro abierto que mira con especial atención y anillos en su mano izquierda. Esa mayor suntuosidad se aprecia también en su casulla, más exuberante que la de su compañero, con profetas o santos bordados en su parte delantera y un formal mucho más rico. Las figuras se encuentran en el interior de una estancia, frente a un vano o puerta abierta que muestra un paisaje con nubes y de un celaje azul intenso, interrumpido en su parte inferior por unos casi imperceptibles paisajes montañosos.

Aunque no se conozcan las medidas del retablo, los datos indican una relación de los lienzos con el realizado para la cabecera del templo de Santa Isabel que menciona el inventario de 1601. Esta pareja de lienzos fue restaurada en el año 2002 y su estudio minucioso reafirma algunas de estas teorías, como el hecho de que las puertas están sensiblemente recortadas y que tanto la tela con la que se realizaron las obras (lino de trama cerrada) como su preparación blanca es idéntica entre $\mathrm{si}^{43}$.

Aparte de estas dos pinturas, se localiza en la clausura de Santa Isabel otro óleo sobre lienzo que es relevante para la reconstrucción de este tríptico. Se trata de una escena de la Visitación, en grisalla, localizada en el vestíbulo de la planta segunda de la clausura [fig. 8]. La obra figura en el libro que se realizó con motivo de la exposición conmemorativa de creación del patronato de Santa Isabel, pero aparece datada como del siglo XIX ${ }^{44}$. Pero, realmente, tanto su ejecución, como la recreación de los personajes, responden a lenguajes anteriores, posiblemente de finales del siglo XVI o primeros años del siglo XVII.

Las similitudes de esta obra con las de las dos tablas de San Eugenio y San Ildefonso son evidentes. Se aprecian analogías en la forma de recrear los celajes, las calidades textiles o el estudio de las luces y las sombras sobre las carnaciones o los ropajes de los protagonistas. Estas afinidades se revelan indiscutibles en aspectos concretos de la obra como, por ejemplo, rasgos fisonómicos, destacando la factura de la barba de san Eugenio, prácticamente idéntica en la grisalla a la del personaje situado detrás de santa Isabel, e identificado como san Zacarías. También los rostros de san Ildefonso y santa Isabel presentan notables equivalencias, como la forma de los labios, la nariz, o el mentón de ambos, ligeramente adelantado. Por último, el diseño de los zapatos, muy parecidos los de san Ildefonso y santa Isabel.

Basándonos en el inventario de 1601, la escena de La Visitación en grisalla debía de estar dispuesta en dos mitades en las caras exteriores de las alas, y por tanto disponerse en sendas pinturas separadas, como se hallan los lienzos de santos ya comentados. Aquí, sin embargo, nos encontramos una narración completa de la escena, sin falta alguna en la composición. Analizando sus medidas $(155 \times 159 \mathrm{~cm})$, se aprecia que la grisalla posee una altura similar a las puertas del tríptico, siendo su ancho algo más del doble de cada una de ellas. Es decir, la suma de los anchos de las dos telas con representación de santos es prácticamente la misma que el total de la escena de La Visitación.

Para remarcar aún más esta teoría, se observa entre las figuras de la Virgen y Santa Isabel, un corte longitudinal, unido a una intensa pérdida de pintura, que se sitúa de extremo superior a inferior de la misma y la divide en dos paños de medidas prácticamente idénticas. Cada hipotético paño casaría con las dos alas de la composición, con representaciones de San Eugenio y San Ildefonso. Por tanto, podríamos decir que son parte de ese mismo conjunto mencionado en el inventario de 1601 y que las tres formaban parte de este desaparecido primer retablo de Santa

\footnotetext{
${ }^{43}$ Agradezco a D ${ }^{a}$ Nayra García-Patrón Santos, conservadora de Santa Isabel, la información prestada. Aunque el informe de restauración lo indica, si nos acercamos a ver las obras in situ, podrá observarse la continuidad de la pintura en los laterales, ya que estas no tienen marco y se aprecia sin problemas la prolongación de la capa pictórica.

${ }^{44}$ Martínez Cuesta, 1990: 88. Agradezco al profesor Ismael Gutiérrez Pastor la indicación de esta pieza y su posible relación con el conjunto estudiado.
} 


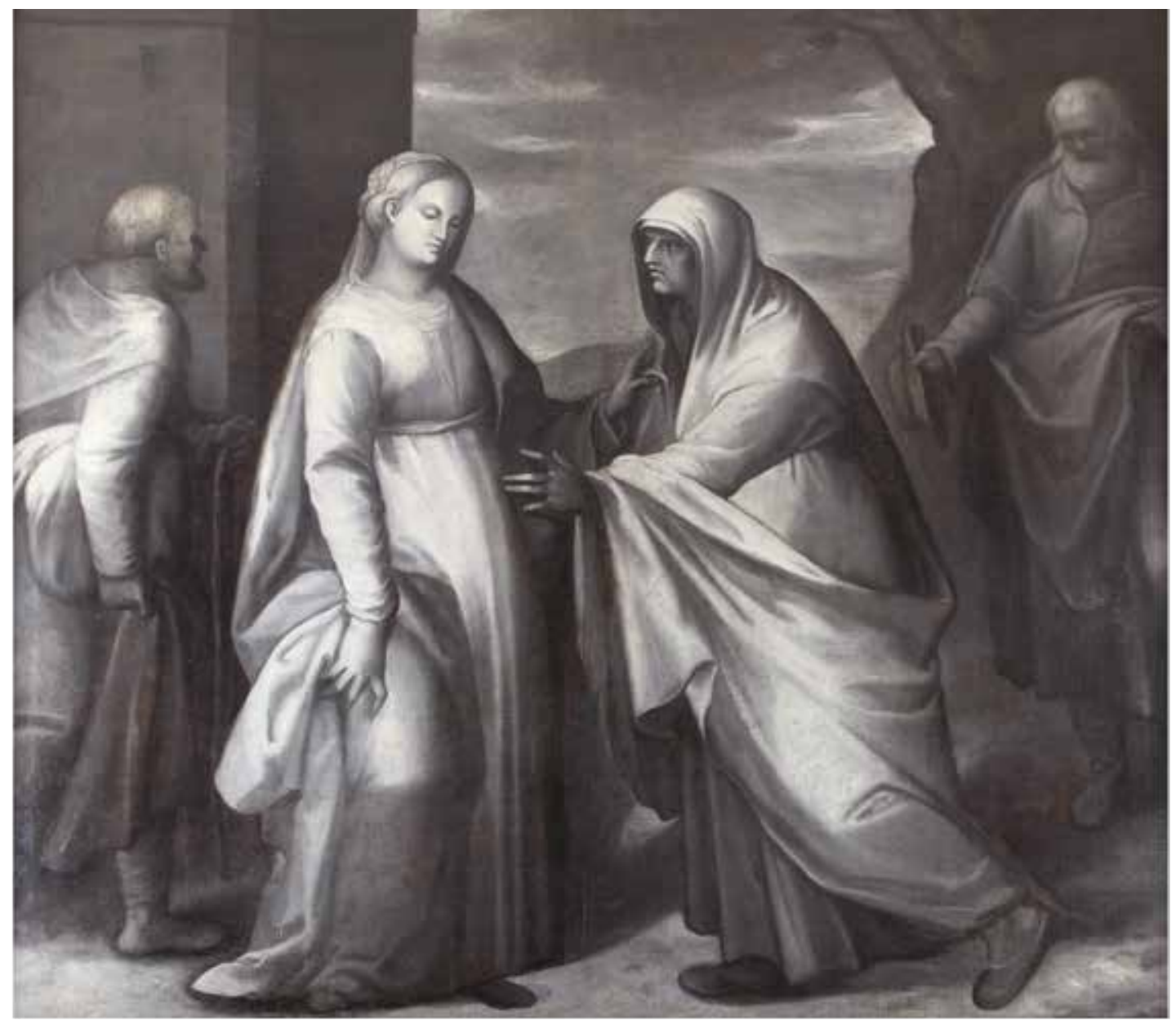

Fig. 8. Anónimo español. La Visitación, h. 1599-1601. Madrid, Convento de Santa Isabel (PI-630748). (C) Patrimonio Nacional.

Isabel la Real. Es interesante resaltar, como esta hipotética separación de las dos figuras, daría como resultado la pérdida de la mano de Santa Isabel, que quedaría pegada al vientre de María, remarcando aún más el mensaje simbólico de la escena.

Posiblemente, cuando se acometió la reforma de ampliación de la iglesia en tiempos de Felipe IV, el retablo resultó de proporciones inadecuadas al nuevo templo, decidiéndose la realización de otro nuevo, de estilo barroco y más relevante hacia $1664^{45}$. Poco después, en 1672, llegó la Inmaculada de Ribera obsequiada por el mismo monarca ${ }^{46}$. Es muy probable, en vista de estos datos, que el tríptico fuese trasladado a la clausura desde el primer momento, desmontado y dispuesto en pinturas independientes, uniendo las dos mitades de la grisalla para tener una obra coherente de $L a$ Visitación. De la escena de la parte central, no se tiene constancia en el convento ${ }^{47}$.

45 Cruz Yábar, 2013: 101

${ }^{46}$ González Asenjo, 2006: 97.

${ }^{47}$ Existe en el Coro alto del monasterio una pintura (PI-19E1845P) que por estar inaccesible no ha podido ser medida, con una escena de La Visitación, en color, y con los mismos protagonistas que la escena en grisalla. Sin embargo, la ficha de Patrimonio Nacional la considera obra del siglo XIX, aspecto coherente tras una inspección ocular. A falta de más datos no se puede establecer ninguna relación con las otras obras. 
Con respecto a la autoría y, a falta de datos concluyentes, las pinturas deben relacionarse con algún pintor cortesano, próximo a artistas italianos tardomanieristas o influidos por ellos. El uso de colores intensos y vibrantes en las pinturas de los dos santos restaurados, el tratamiento de las telas, de amplios pliegues apenas quebrados, así como el modelado suave de todos los rostros, blandos y sin apenas contrastes lumínicos, refuerzan esta hipótesis.

Dentro de esta posible nómina debemos considerar no solo artistas que habían trabajado en el Real Monasterio de San Lorenzo de El Escorial a finales del siglo XVI, o realizando trabajos a las órdenes de Felipe III en la Casa Real de El Pardo en los inicios del siglo XVII ${ }^{48}$. También es significante recordar a aquellos jóvenes pintores que formaron y emularon su estilo gracias a instituciones como la Academia de Madrid, con una clara voluntad pedagógica y docente ${ }^{49}$.

En esta relación de artistas del momento, debemos mencionar a los hermanos Carducho, en especial Vicente, cuya actividad y prestigio fue constante y creciente en el ámbito palatino y cuyas formas anatómicas resultan similares ${ }^{50}$. También merece ser citado el toscano Patricio Cajés, cuya gama cromática, ácida y sin apenas sombras que modulen, se acerca a la de los santos patronos del Arzobispado de Toledo o incluso con su hijo, Eugenio Cajés, que ya por esas fechas estaba establecido en Madrid ${ }^{51}$. Con este último, se aprecian semejanzas con su pintura El abrazo de San Joaquín y Santa Ana, datada hacia 1605 y conservada en la Real Academia de Bellas Artes de San Fernando de Madrid ${ }^{52}$. Esta obra guarda similitudes cromáticas y formales con los santos del convento madrileño, en especial al comparar la figura de san Joaquín con la de san Eugenio, en aspectos como la factura de la nariz o de la barba, particularidades que se aprecian mejor si se compara con el boceto del cuadro de la Academia, que se conserva en la colección Granados ${ }^{53}$.

En cuanto a la iconografía, san Eugenio y san Ildefonso estaban muy relacionados con la Archidiócesis de Toledo, a la que por entonces pertenecía Madrid. Aunque este patrocinio de los dos santos podría parecer referencia exclusiva al patronazgo de Gaspar de Quiroga y Vela, hay que recordar que los santos del Arzobispado de Toledo lo son también del rey de España ${ }^{54}$. Por tanto, esta elección no es trivial y responde a representar a los dos patronos que se mencionan en el inventario de 1601. La inclusión de ambos santos toledanos estaba plenamente justificada para mostrar el patronato del purpurado y del monarca. Los dos padres de la iglesia hispano-visigoda, nacidos en la ciudad imperial y con relaciones de parentesco entre sí (san Eugenio era tío de san Ildefonso), desempeñaban una importante labor simbólica.

Mientras san Ildefonso era el patrón de la Archidiócesis de Toledo, la traída del cuerpo incorrupto de su tío desde Francia en el año 1567, gracias a Felipe II, fue motivo de celebración ya que a partir de ese momento descansarían en la catedral primada ${ }^{55}$. Este hecho, de gran relevancia para la comunidad religiosa de Toledo no había transcurrido durante el mandato de Quiroga, pero la gran relevancia del hecho y su cercanía a la gestión del purpurado fueron decisivos para la inclusión de dichos santos en el retablo. La intercesión en este hecho de Felipe II debió ser otro punto a favor para su elección, tanto por los lazos familiares de su hijo, como por la importancia del fallecido monarca en la creación del recogimiento de Santa Isabel.

El monarca, que pasó a administrar todos los bienes de Gaspar de Quiroga a su muerte, realizó el encargo en nombre del religioso con cargo a su legado, respetando así la voluntad del cardenal ${ }^{56}$. Poco después, en 1603, los testamentarios de don Gaspar de Quiroga y Vela aplicaron una gran suma de dinero tras un acuerdo con el rey. Además, se establecieron ciertas cargas de misas y

\footnotetext{
48 Lapuerta Montoya, 2002: 305.

49 Pérez Sánchez, 1986: 47.

50 Angulo Íñiguez/Pérez Sánchez, 1969: 89.

51 Angulo Íñiguez/Pérez Sánchez, 1969: 213.

52 Angulo Íñiguez/Pérez Sánchez, 1969:217.

53 Pascual Chenel, 2019: 285.

54 Rodríguez Moya, 2007: 160.

55 Fernández Collado, 1999: 178.

56 Cavero de Carondelet, 2016: 125.
} 
aniversarios por el alma del cardenal, así como poner sus armas, pero "sin letrero", debajo de las del rey en las puertas del colegio ${ }^{57}$.

Esta profunda relación del religioso con el colegio fue clave en estos primeros años de la fundación y tuvo mucho peso en las decisiones de la Casa Real. De hecho, cuando la reina propuso traer a las religiosas agustinas desde la calle Príncipe a Santa Isabel, se le recomendó no hacerlo ya que se quería "evitar comentarios desfavorables a la soberana que tal vez pudieran mas tarde surgir" al haber sido dotado por el cardenal Quiroga ${ }^{58}$.

No obstante, la entrada de la comunidad de monjas agustinas recoletas en el edificio en el año 1610 , con sus propios problemas, pleitos y necesidades, así como la notable evolución que experimentaron después la institución y el edificio, hicieron que se olvidara su legado rápidamente. Un año después comenzó la construcción de la nueva iglesia, según diseño de fray Alberto de la Madre de Dios bajo la dirección de Francisco de Mora que fallecería ese año ${ }^{59}$. Felipe III donó madera de Valsaín y mármoles para realizar el nuevo templo ${ }^{60}$.

Por tanto, la dotación referida en estas líneas evidencia que la relación entre Felipe III y la fundación piadosa de Santa Isabel no era tan fría como se pensaba. Siempre se supuso que fueron Felipe II y su nieto Felipe IV los verdaderos impulsores de este recogimiento. A la vista de estos datos, Felipe III y posteriormente su mujer tuvieron muy en cuenta esta fundación tanto por su sustento económico como por la decoración de sus interiores ${ }^{61}$.

Este afecto hacia el recogimiento es algo que ya se dejaba entrever en algunos testimonios de la época, como el del historiador León Pinelo, quien comenta que en el año 1603 los reyes hicieron una visita a Madrid desde Valladolid. En ella, la reina Margarita de Austria quedó aposentada en las Descalzas Reales, saliendo solo en dos ocasiones, "una para compañía de Jesús y otra el Colegio de Santa Isabel, a ver los niños y niñas que allí se recogían"62. Con estos testimonios, queda claro que su implicación fue mayor, y que la llegada de las monjas fue un intento de mejorar la situación del recogimiento.

De esta manera se aclara la primera etapa del patronato, así como la dotación de la iglesia del Real Colegio y se documentan y contextualizan algunas piezas que se encontraban y encuentran en sus instalaciones. Este inventario, además, muestra una etapa desconocida del rey Felipe III y su mujer, Margarita de Austria, como promotores de este real convento, justo antes del traslado temporal de la corte a Valladolid.

\section{BIBLIOGRAFÍA}

Álvarez y Baena, Josef Antonio (1786): Compendio histórico de las grandezas de la coronada Villa de Madrid, corte de la monarquía de España. Madrid: Reed. El Museo Universal.

Angulo Íñiguez, Diego / Pérez Sánchez, Alfonso Emilio (1969): Historia de la Pintura española. Escuela madrileña del primer tercio del siglo XVII. Madrid: Instituto Diego Velázquez.

Cavero de Carondelet, Cloe (2016): Una Villa toledana del Quinientos: el cigarral del cardenal Quiroga. Toledo: Real Fundación de Toledo.

Cruz Yábar, Juan María (2013): El arquitecto Sebastián de Benavente (1619-1689) y el retablo cortesano de su época. Tesis doctoral inédita presentada en la Universidad Complutense de Madrid.

Cruz Yábar, María Teresa (1996): La tapicería en Madrid (1570-1640). Madrid: CSIC.

Delaforce, Angela (1982): "The collection of Antonio Pérez, Secretary by Philip II". En: The Burlington Magazine, CXXIV, 957, Londres, pp. 742-752.

\footnotetext{
57 Sáenz Ruíz-Olalde, 1990: 64.

${ }^{58}$ Sáenz Ruíz-Olalde, 1990: 60.

59 Tovar Martín, 1975: 322

${ }^{60}$ Llaguno y Amirola, 1829: 346.

${ }^{61}$ Los reyes fomentaron una política de patronazgo religioso, con importantes donaciones y legados, para perpetuar la vinculación de la corona con ellos. De todos los ejemplos posibles, destaca la creación y engalanamiento del Monasterio de la Encarnación entre 1611 y 1616, tras la llegada de unas monjas que se habían marchado de Santa Isabel.

${ }^{62}$ Guzmán, 1617: 105-106.
} 
Ezquerra del Bayo, Joaquín (1926): “Casas de recreo”. En: Boix y Merino, Félix (ed.): Exposición del Antiguo Madrid, Madrid: Gráficas Reunidas, pp. 110-124.

Fernández Collado, Ángel (1999): La catedral de Toledo en el siglo XVI. Vida, arte y personas. Toledo: Diputación provincial de Toledo.

González Asenjo, Elvira (2006): Don Juan de Austria y las Artes 1629-1679. Madrid: Fundación Arte Hispánico.

González Palencia, Ángel (1918): "Fragmentos del archive particular de Antonio Pérez, secretario de Felipe II". En: Revista de Archivos, Bibliotecas y Museos, 39, Madrid, pp. 354-364.

Guzmán, Diego (1617): Reina católica: vida y muerte de doña Margarita de Austria Reyna de Espanna al Rey don Phelippe III N. Sr. Madrid: Luis Sánchez.

Lapuerta Montoya, Magdalena de (2002): Los pintores de la corte de Felipe III. La casa Real de El Pardo. Madrid: Fundación Caja Madrid.

Llaguno y Amirola, Eugenio (1829): Noticias de los Arquitectos y Arquitectura de España desde su Restauración. Tomo III. Madrid: Imprenta Real.

Marañón y Posadillo, Gregorio (1948): Antonio Pérez. Madrid: Espasa-Calpe.

Martín, Fernando A. (1979): "Capilla de Palacio y Monasterios de la Encarnación (Madrid) y El Escorial. Cálices limosneros”. En: Reales Sitios, 62, Madrid, pp. 12-16.

Martínez Cuesta, Juan (1990): "La pintura del Real Convento de la Visitación. Catálogo". En: Real Fundación del convento de Santa Isabel de Madrid. Madrid: Fundación Yanes.

Molina Campuzano, Miguel (1960): Planos de Madrid de los siglos XVII y XVIII. Madrid: Instituto de Estudios de la Administración Local.

Panizo Delgado, Ángel (2012): "Santa Marta de Tera: un cáliz limosnero regio". En: Brigencio: revista de estudios de Benavente y sus tierras, 21-22, Zamora, pp. 241-246.

Pascual Chenel, Álvaro (2019): "Dibujar, especular y más dibujar. Los Carducho y Cajés, entre la formación italiana y la escuela española". En: Boletín de Arte, 40, Málaga, pp. 281-293.

Pérez Sánchez, Alfonso Emilio (1986): Historia del dibujo en España. De la Edad Media a Goya. Madrid: Cátedra.

Robles Muñoz, Cristóbal (2018): La Santa Sede y La II República. De la conciliación al conflicto (1931). Madrid: ACCI.

Rodríguez Moya, Inmaculada (2007): "Los reyes santos". En: Mínguez Cornelles, Víctor (ed.): Visiones de la monarquía hispánica. Castellón de la Plana: Universidad Jaume I, pp. 133-170.

Sáenz Ruíz-Olalde, José Luis (1990): Las Agustinas Recolectas de Santa Isabel la Real de Madrid, cuatro siglos de historia (1589-1989). Madrid: Augustinus.

Sánchez Hernández, Leticia (1990): “El convento de Santa Isabel: Madrid 1589-1989”. En: Real Fundación del convento de Santa Isabel de Madrid. Madrid: Fundación Yanes.

Tovar Martín, Virginia (1975): "Juan Gómez de Mora en el convento real de Santa Isabel y en la iglesia de Ntra. Sra. de Loreto de Madrid”. En: Boletín del Seminario de Estudios de Arte y Arqueología, 40-41, Valladolid, pp. 321-342.

Ungerer, Gustav (1974-1975): "La defensa de Antonio Pérez contra los cargos que se le imputaron en el proceso de visita (1584)”. En: Cuadernos de Historia Jerónimo Zurita Institución Fernando el Católico, 27-28, Madrid, pp. 63-149.

Zapata, Luis (1859): "Miscelánea de Zapata". En: Memorial histórico español. Colección de documentos, opúsculos y antigüedades, que publica la Real Academia de la Historia, XI, Madrid, pp. 242-253.

Fecha de recepción: $15-\mathrm{V}-2020$

Fecha de aceptación: 17-VII-2020 